\title{
Article \\ Measuring the Construction Project Resilience from the Perspective of Employee Behaviors
}

\author{
Zheng He ${ }^{1,2}$ (), Genda Wang ${ }^{1,3}$, Huihua Chen ${ }^{1}$, Zhuojun Zou ${ }^{1, *}$, Hongyan Yan ${ }^{2}$ and Linlin Liu ${ }^{1}$ \\ 1 Railway Campus, Central South University, Changsha 410075, China; he0814@csu.edu.cn (Z.H.); \\ wang0521@csu.edu.cn (G.W.); chh@csu.edu.cn (H.C.); divine@csu.edu.cn (L.L.) \\ 2 School of Engineering Management, Hunan University of Finance and Economics, Changsha 410205, China; \\ yanhongyan@hufe.edu.cn \\ 3 High Speed Train Research Center, Central South University, Changsha 410075, China \\ * Correspondence: 203021@csu.edu.cn
}

check for

updates

Citation: He, Z.; Wang, G.; Chen, H.; Zou, Z.; Yan, H.; Liu, L. Measuring the Construction Project Resilience from the Perspective of Employee Behaviors. Buildings 2022, 12, 56. https://doi.org/10.3390/ buildings12010056

Academic Editors: Tao Wang, Jian Zuo, Hanliang Fu and Zezhou Wu

Received: 9 December 2021

Accepted: 4 January 2022

Published: 6 January 2022

Publisher's Note: MDPI stays neutral with regard to jurisdictional claims in published maps and institutional affiliations.

Copyright: (c) 2022 by the authors. Licensee MDPI, Basel, Switzerland. This article is an open access article distributed under the terms and conditions of the Creative Commons Attribution (CC BY) license (https:/ / creativecommons.org/licenses/by/ $4.0 /)$.

\begin{abstract}
The increasing developmental potentiality for the construction industry brings the huge challenge to make up the limitation of traditional construction project management mode when adapting to the Sustainable Development Goals (SDGs). Due to the high energy and resource consumption for the construction projects, there are a large number of uncertainties and disturbances in achieving resilient urban infrastructure. Studying construction project resilience (CPR) is imperative. However, prior studies preferred to measure resilience by systemic indicators, which are complex and unfriendly. Studying CPR from the perspective of employee behavior (EB) remains rare. Hence, this study proposed a social network analysis (SNA) methodology to overcome the research gap. Firstly, six EBs are identified by the systematic literature review (SLR). Then, the critical employees (CEs) and their interrelationships are investigated to form the social network. Six SNA parameters including density, degree centrality, betweenness centrality, efficiency, constraint, and cliques are selected to model the EBs, namely PMT cohesion, the identity of the project culture, formal behavior between employees, collaboration efficacy, informal social constraints, and reciprocity and mutual trust. Finally, the value of CPR is obtained and the strategies for improving the CPR are proposed from four characteristics: robustness, redundancy, rapidity, and resourcefulness. The findings provided a simple and effective techniques to measure the CPR and could benefit the project manager to improve the CPR by exerting accurate strategies to the EBs in poor performance.
\end{abstract}

Keywords: construction project resilience; resilient infrastructure; critical employee; employee behaviors; social network analysis; HOPSCA project

\section{Introduction}

The increasing development of the construction industry in most countries has brought tremendous challenges to the social environment, energy, and resources [1,2]. Meanwhile, the extensive and energy-consuming way of obtaining construction products in the construction industry brings more threatens to social and economic development [3,4]. In the past decade, an increasing number of construction enterprises and construction project management organizations [5,6] apply the lean construction management [7-9] to improve their construction productivity and project performance. As a respect- and relationship-oriented construction project management, it is a new and transformational way to design and build capital facilities [10,11]. Although the implementation of lean production management [12] caused a high yield in the process of planning, designing, construction and operation in a contrition project [13-15], a series of issues are faced and challenged by the construction managers and scholars. One of the most significant issues are the uncertainties and disturbances derived by energy shortage and environmental degradation, which are considered to be one of the 
most critical obstacles in achieving SDGs. SDGs require the construction industry to adapt a more resilient mode to tackle the uncertainties and disturbances.

More and more practitioners in a construction project have grown more aware of the limitation of the current construction project management framework $[16,17]$. The concept of resilience is widely implemented to tackle with the uncertainties and disturbances issues in different fields [18-20]. However, there is a lack of studies considering resilience in the construction project. The completion of a construction project is a complex system engineering that not only requires a tremendous resource allocation but also needs the arrangement of construction activities [21,22]. Therefore, the roles of humans in a CPMO are of great significance where the key construction activities are conducted by the employees [23]. From these perspectives, it is imperative to take human behaviors as the most vital and critical factor of the construction project management [24]. By doing these, the organizational way of the construction project would change from a leader-oriented style [25-28] to the to an intelligent and initiative one.

Hence, to overcome the present research gap, this study aims to measure the CPR by investigating the different EBs of critical employees and establishing a complex employee relationship network (ERN) to reveal the strength of the connections. Thereafter, the SNA based methodology is used to model the ERN where each EB is characterized by SNA parameters. The output of SNA could finally be utilized to calculate the CPR. The methodology could benefit the decision-makers to apply a simple and highly effective tool to measure the CPR by imputing the quantized EBs and the strength of the interrelationship between CEs.

\section{Literature Review}

In the past decade, the construction project management mode is adapted to the lean management framework [29-31]. The lean management framework could bring a number of advantages in improving the project performance [8] and simplifying the management process [32-34]. Within such a traditional construction project management framework, certain technical standards and business processes toward construction activities are determined $[35,36]$. Under the lean management framework, the employee relationships in a CMPO are mainly limited to the formal relationships which are constrained by a series of contractual relationships [37-41].

There exist a large body of studies focused on the role relationships in a construction project. For instance, Malik et al. [42] conducted a study to explore the role relationships by analyzing the function of communication and construction projects from the perspective of project issues and conflicts. They revealed that the task conflicts between each project role have a positive influence on the relations. They argued that the members of a project management team (PMT) would be asked to use different ways to fulfill a certain task. Similarly, the conflicts on the project process and roles' relationship affects negatively the communication and project success. Gardounis et al. [43] raised a conceptual framework for SNA of BIM in construction projects including formal relationships through contractual arrangements, informal communication relationships, and the relevant changes on roles and relations. They found that an SNA conceptual framework could help PMT to arrive at project processes and their variability.

Similarly, prior studies explored the impact of leadership [44,45] on employee performance. Their research shows that the preference of the leader directly affects the behavior of the employee [46-48]. Meanwhile, there are a small group of scholars who regard the employment relationship as an exchange of effort, loyalty, and economic interests (such as social security, wages, welfare, etc.) [49-51], social sentiment and interests [52,53]. In these studies, social exchange theory provides a theoretical basis for this kind of employee-employer relationship [54-56]. It believes that as a response to different stimuli in the organization, the positive or positive relationship between informal employees and employers is weaker than that of regular employ- 
ees [57-60]. Unlike regular employees, informal employees do not have long-term job security and rarely enjoy the training and career development plans provided by the company [61,62].

Moreover, a number of previous studies have discussed the influence of the strength of these relationships on project performance from the contractual relationship of the project. For instance, Meng (2012) [63] carried out the research scheme of the questionnaire from the perspective of project performance to study the construction industry in British. The questionnaire was scored by the following indicators: common goals, benefit and pain sharing, trust, no responsibility culture, joint work, communication, problem-solving, risk distribution, performance measurement, and continuous improvement. His research found that the deterioration of employee relationships may increase the likelihood of poor project performance. By improving certain aspects of the relationship, poor project performance can be effectively reduced.

Although prior studies have discussed the formal relationships and informal relationships in a CPMO, there is little literature that considers the employment relationship under the current managemental framework. Moreover, each employee relationship could be studied and indicated through the characteristic of employee behaviors [3,64-66]. For instance, Xue et al. [67] investigated the stakeholder conflicts in megaprojects of the Hong Kong-Zhuhai-Macao Bridge. They explored the changes of stakeholder relationships in the whole life cycle of a construction project and thereafter they divided the stakeholder groups into 5 clusters, namely local industry, green group, supervision group, construction group, and governmental organizations.

Toward the construction project resilience, although there existed some literature that discussed the concept and application of resilience methodology, it still has few studies investigating the resilience from the perspective of EBs, either using social network analysis. The traditional goal of SNA is to identify and describe the structure of the network through the use of graph theory $[68,69]$. When collecting data from a bounded network, individuals usually identify connections with other network members $[70,71]$. The existence or non-existence of these relationships is meaningful because these associations describe the type of network (such as friendship network, suggestion network), and the relationship reflects a specific type of relationship between network members [72,73]. In SNA, the connection is often directional, in which when an individual is identified to a node, it represents the source of the node, and when the relationship changes from an element in the SNA, it represents the import of the element [74,75]. Each relationship can also have a weight. This weight can be the strength of the relationship (excluding weak or strong relationships) or other information about the link, such as the type of suggestion or shared information. When the relationship has weight, it is called valuable network data [76-78]. In addition to graphically describing the structure of the network (i.e., the element expressed as a "node" and the relationship expressed as a link or "edge"), many metrics are used to characterize individuals (such as centrality), duality (such as connectivity) [79-81], Reciprocity, group (such as clustering, closed) or the entire network (such as density, average vertex degree) [82-84].

The objectives of this study were as follows: (1) investigating the employee behaviors using data mining, (2) building the employee relationship network using SNA, and (3) modeling the employee relationship network by determining the CRs.

The organization of the paper and the logic framework are as followed. Section 3 raises the methodology of this study. Section 4 implements the proposed methods through a case study in China, and Section 5 makes the discussion. Section 6 lists the summary and conclusions. 


\section{Methodology}

This section may be divided into subheadings. It should provide a concise and precise description of the experimental results, their interpretation, as well as the experimental conclusions that can be drawn.

\subsection{Investigating the Employee Behaviors Using Systematic Literature Review}

Systematic literature review (SLR) was selected at first to investigate the EBs in previous literature. SLR is an effective literature review methodology with the advantages of avoiding the omission of key literature and subjective errors. During the process, we employed 3 different types of databases to collect the initial data: Scopus, Google Scholar, and Web of Science. The source of literature is limited to peer-reviewed journals published in English. The searching keywords are selected to "employee behaviors", "construction project", "formal and informal relationships". The time span is set to "2011-2021". There are two steps in this process: the searching process and the screening process. During the searching process, 186 papers were identified for the next screening process.

In the screening process, we first removed the paper which is duplicated, and made a title filtering. After this step, 121 papers remained. Then, we processed the abstract filtering by reading the abstract of the 121 papers manually and removing the papers whose abstracts are not directly related to the EBs. After this step, 84 papers remained. Thereafter, we conducted the full-text reading toward the remaining 84 papers. Then, 42 papers remained. Finally, we reviewed the references from the remained 42 papers and picked up the omitted papers which are not included in the database but have useful information for the study.

After the supplemental process, 54 papers are finalized to extract the EBs manually. The flowchart of the two steps of SLR is presented in Figure 1.

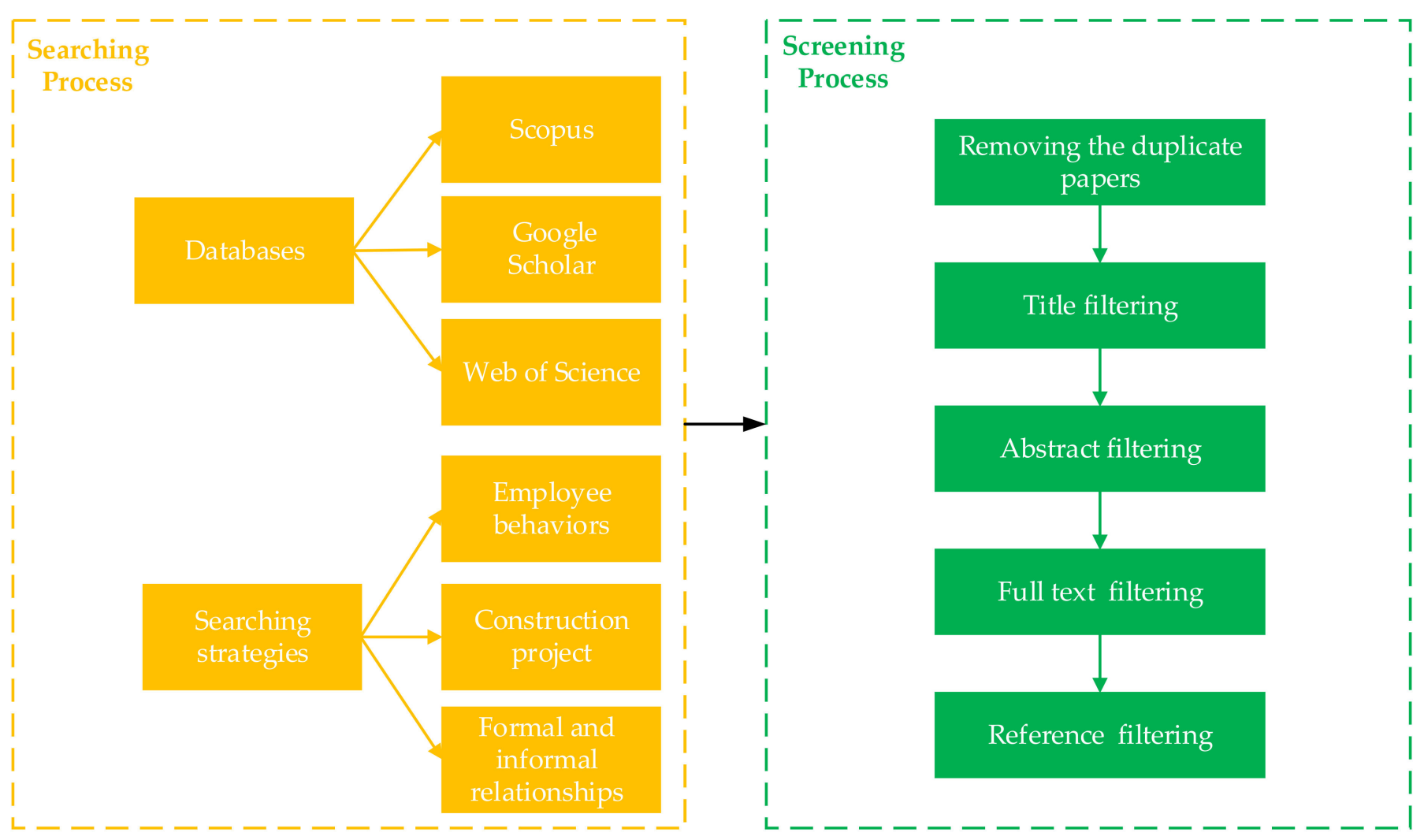

Figure 1. Flowchart of searching and screening process in SLR. 
Finally, 6 employee behaviors that are used to depict the complex employee relationship are obtained. These EBs include PMT cohesion (C1), the identity of the project culture (C2), formal behavior between employees (C3), collaborate efficacy (C4), informal social constraints (C5), reciprocity and mutual trust (C6).

The extracted EBs and the data of the source are presented in Table 1.

Table 1. Extracted employee behaviors and the data of source.

\begin{tabular}{ccc}
\hline Code & Employee Behaviors & Data of Source \\
\hline C1 & PMT cohesion & {$[85-90]$} \\
\hline C2 & Identity of the project culture & {$[91-94]$} \\
\hline C3 & Formal behavior between employees & {$[38,95-97]$} \\
\hline C4 & Collaborate efficacy & {$[98-102]$} \\
\hline C5 & Informal social constraints & {$[103-106]$} \\
\hline C6 & Reciprocity and mutual trust & {$[24,33,107-110]$} \\
\hline
\end{tabular}

\subsection{Building the Employee Relationship Network Using SNA}

The employee behaviors in the CPMO on the employees and their interrelationships could generate a kind of complex network, which can be studied by the social network analysis (SNA) approach. The SNA method is a structural analysis (SA) method that is applied across multiple disciplines. It can provide a mathematical model to study the relationship structure and attributes of social networks [111,112]. The significance of SNA is that it can carry out precise quantitative analysis and visual analysis of various relationships between network targets, thereby providing a quantitative mathematical model for constructing a certain middle-level theory and testing empirical propositions $[81,113,114]$.

Through demonstrating a logic roadmap or network graph, the characteristic of the employee relationships and the employee behaviors could be explored. It put forward that employees in a CPMO are rooted within a social network which includes formal and informal relationships and their behavior and behavioral results are influenced by such social network.

Hence, we use 4 descriptive characteristics and network parameters to measure the employee behaviors involving cohesion, centrality, structural hole, and subgroup.

\section{(1) SNA-Cohesion}

We use the network density analysis method to measure the strength of the SNACohesion in the employee relationship network. The number of the connection between each CE determines the strength of the density where the social network can affect the attitudes and employee behaviors in a CMPO. Therefore, we obtain the density of each CE through the UCINET platform.

\section{(2) SNA-Centrality}

We select 2 sets of SNA-Centrality parameters to depict the identity of the project culture (C2) and formal behavior between employees (C3). The degree of SNA-Centrality demonstrates the power and authority of CEs in a CMPO. The betweenness centrality represents the communication and knowledge sharing function of a CE. It is recognized as the indicator of the mutual activities among the CEs.

(3) SNA-Structural hole

The SNA-Structural hole is used to analyze the nonredundant link between any two CE. Taking the holistic and systematic consideration into the whole social network, it acts as a hole in the structure of the network. From this perspective, we apply collaborative efficacy (C4) and informal social constraints (C5) to descript the SNA-Structural hole parameter. 


\section{(4) SNA-Subgroup}

The SNA-Subgroup refers to the degree of closeness between the certain CEs in the social network where they have reciprocity with each other and combine into a substantial subgroup. Therefore, we use reciprocity and mutual trust (C6) to explain the clique in the social network.

The parameters of SNA including the employee behaviors are presented in Table 2.

Table 2. Parameters of SNA include employee behaviors.

\begin{tabular}{|c|c|c|c|}
\hline \multicolumn{2}{|c|}{ Employee Behaviors } & Indicators & Parameters \\
\hline $\mathrm{C} 1$ & PMT cohesion & Cohesion & Density \\
\hline $\mathrm{C} 2$ & Identity of the project culture & \multirow{2}{*}{ Centrality } & Degree centrality \\
\hline $\mathrm{C} 3$ & Formal behavior between employees & & Betweenness centrality \\
\hline $\mathrm{C} 4$ & Collaborate efficacy & \multirow{2}{*}{ Structural hole } & Efficiency \\
\hline $\mathrm{C} 5$ & Informal social constraints & & Constraint \\
\hline C6 & Reciprocity and mutual trust & Subgroup & Cliques \\
\hline
\end{tabular}

\subsection{Modeling the Employee Relationship Network by Determining the CEs}

Through the investigation on the EBs of each CE, the PMT can obtain a certain reference to improve the performance of employees. In terms of the project level, 12 significant CEs are identified in this study. They include deputy project manager (S1), business manager (S2), chief engineer (S3), cost engineer (S4), safety and quality engineer (S5), procurement engineer (S6), construction crew (S7), site engineer (S8), construction contractor (S9), consultant (S10), designer (S11) and supervisors (S12).

\subsection{Calculating the Construction Project Resilience}

After establishing the CEs network, the nodes of the conducted social network are modeled as identified critical employees. Thereafter, the connections between the nodes are modeled as the interrelationships between the CEs. The weight of the links in the social network are determined by the designed Liszt five points scale. The values $(1,2,3,4,5)$ are marked by five levels, namely very weak, weak, normal, strong, very strong. Then, the social network was generated by UCNET and the social network indicators were used to represent the EBs (Table 2). Finally, the CPR is calculated through Equation (1).

$$
\mathrm{CPR}=\sum_{i=1}^{n} \frac{C i-\min C i}{\max C i-\min C i}
$$

\subsection{Implements on Improving the Construction Project Resilience}

The utilizing of resilience analysis owns the significant advantages for compensating for the traditional risk and disaster management framework. Bruneau et al. [115] proposed a classic measurement framework for the " $4 \mathrm{R}$ " characteristics, involving robustness, redundancy, rapidity, and resourcefulness, to describe the performances of the resilience. The framework holistically explains resilience in multi-dimensions. Hence, this study calculates the $4 \mathrm{R}$ characteristics of resilience based on the framework and proposes strategies for improvement, correspondingly.

In the framework, the capabilities of the construction project for facing uncertainties and disturbances are reflected by the $4 \mathrm{R}$ characteristics of resilience. The first characteristic, i.e., robustness is described with the centrality of each CE. Thus, according to Table 2, $2 \mathrm{EBs}$, including "identity of the project culture (C2)" and "formal behavior between employees (C3)" are represented by the robustness. The stronger and tighter relationship between the CEs bring the higher centrality and finally, form the capability to against the uncertainties and disturbances. 
The second characteristic, i.e., redundancy, is described with the structural hole of each CE. Thus, according to Table 2, two EBs, including "collaborate efficacy (C4)" and "informal social constraints (C5)" are represented by the redundancy. Two pairs of structural hole parameters, which are efficiency and constraint, are selected to indicate the collaborative efficacy and informal social constraints. The number of structural holes of the construction project reflects the strength of the redundancy of it.

The third characteristic, i.e., rapidity, is described with the cohesion of each CE. Thus, according to Table 2, PMT cohesion (C1) is represented by the rapidity with the parameter of density. The higher density of the CE network reveals the quicker communication among the CEs, where the construction project is better able to respond to the uncertainties and disturbances.

The fourth characteristic, i.e., resourcefulness, is described with the subgroup of the SNA indicator, which is described by the EB of reciprocity and mutual trust (C6). The parameter cliques are used to characterize the C6. The number of the cliques indicates the solutions and strategies the CEs have to address the uncertainties and disturbances.

\section{Case Study}

\subsection{Background of the Selected Construction Project}

Located in the Furong district of Changsha City in China, the Changsha international finance square (referred to hereafter as IFS) was selected as the studied case in this research. It is the largest urban complex of hotels, offices, parks, shopping malls, clubs, and apartments (HOPSCA) project in Hunan and it can provide a comprehensive financial operation mode.

The total investment of the project is over 20 billion, and the total construction area is about 1.02 million square meters, including the commercial part covering 2 floors underground and 7 floors above ground and two connected tower buildings. It is currently the largest investment property project of the Wharf Group. The project with the tallest building and the largest commercial area. The main tower T1 has a total height of $452 \mathrm{~m}$ with 95 floors, which is currently the tallest building in Hunan Province, and the auxiliary tower T2 has a total height of $315 \mathrm{~m}$ with 65 floors.

\subsection{Determining the Components of the SNA Model}

According to the discussion in Section 3.3, S1 to S12 served as the 12 critical employees are conducted as the nodes of the SNA model. Thereafter, we use the unidirectional link to represent the interrelationship between the 12 CEs. The weight of the links can be obtained as follows.

We carried out semi-structured interviews with 26 interviewees who undertook the construction activities of the project.

Establishing the rigorous principles to select these interviewees is crucial in the present study because it could help to obtain valid results by ensuring the selected CEs are qualified to complete the interview pertaining to the case study. The rigorous principles to select these interviewees were implemented from the following three perspectives. Firstly, the selected CEs should own sufficient experience (more than 4 years) for participating in the related construction project and have enough project management knowledge. Secondly, each selected $\mathrm{CE}$ should have a clear role in the construction project and know their responsibility. Third, they should have relatively steady positions in the PMT. Their age, sex, and professional experience are taken into consideration accordingly. The profiles of the selected interviewees are presented in Table 3.

Moreover, at the beginning of the interview, the selected CEs are required to review the key participation processes of the selected construction project, their interrelationship and the communications, etc. Thereafter, the standardized interview adapting Liszt five levels scale was conducted. During the interview, these key participants of the construction project were asked to point out their own relationship with others by scoring the values from 1 to 5 . 
Table 3. Profiles of the interviewees.

\begin{tabular}{ccccc}
\hline CEs NO. & $\begin{array}{c}\text { Roles in the Construction } \\
\text { Project }\end{array}$ & Years & Participants & Percentages \\
\hline 1 & Deputy project manager & 10 years & 2 & $7.69 \%$ \\
\hline 2 & Business manager & 8 years & 1 & $3.84 \%$ \\
\hline 3 & Chief engineer & 8 years & 2 & $7.69 \%$ \\
\hline 4 & Cost engineer & 5 years & 2 & $7.69 \%$ \\
\hline 5 & Safety and quality engineer & 3 years & 2 & $7.69 \%$ \\
\hline 6 & Procurement engineer & 8 years & 3 & $11.53 \%$ \\
\hline 7 & Construction crew & 5 years & 3 & $11.53 \%$ \\
\hline 8 & Site engineer & 5 years & 4 & $15.38 \%$ \\
\hline 10 & Construction contractor & 7 years & 2 & $7.69 \%$ \\
\hline 11 & Consultant & 5 years & 3 & $11.53 \%$ \\
\hline 12 & Designer & 10 years & 3 & $11.53 \%$ \\
\hline
\end{tabular}

\subsection{Establishing the Final SNA Model}

After the nodes and links of the SNA model were determined, the equivalent process for converting the relationships among the nodes to a $0-1$ binary matrix was conducted, where the scores ranked in the ranging of 0 to 2 was assigned to 0 and the scores ranked in the ranging of 3 to 5 was assigned to 1 . Thereafter, the edges of the SNA model are determined by the rules: if the value between two CEs is 1 , an undirected arrow is used to represent the relationship between the two nodes. If the value between any two CEs is 0 , there is no relationship between the two nodes.

Finally, the UCINET 6.0 platform was employed to generate the SNA model and draw the network graph (Figure 2). Through using the built-in functions of the UCINET, the SNA indicators for each EB were calculated. Thereafter, the resilience of the construction project could be obtained using Equation (1).

\subsection{Results and Analysis}

(1) SNA graph and the descriptions

The SNA graph reveals that S2 and S6 own the most links in the entire graph, which indicates that S2 and S6 have the closest relationship with other CEs. The SNA model represents the connections between CEs and the strength of the relationship under a certain disturbance status. The structure and strength of the SNA model are dynamic and adapted to the changes of the disturbance status before, during, and after the disaster period. The number of links between nodes of the SNA model may increase due to the higher degree of intimacy between the CEs.

(2) Employee behaviors indicators

As is presented in Table 2, we used 6 SNA parameters as the indicators to model the EBs (C1 to C6). Hence, the EBs could be measured and reflected by the SNA parameters which are dynamically determined by the connections of the CEs and their strength. In the present study, the employee behaviors analysis for each critical employee has been carried out. The employee behaviors for each critical employee are presented in Table 4.

(3) The construction project resilience

After obtaining the indicators of the employee behaviors for each critical employee, we conducted the normalizing process and the results were used to calculate the CPR by Equation (1). The final CPR of the selected construction project is 53.13 . 


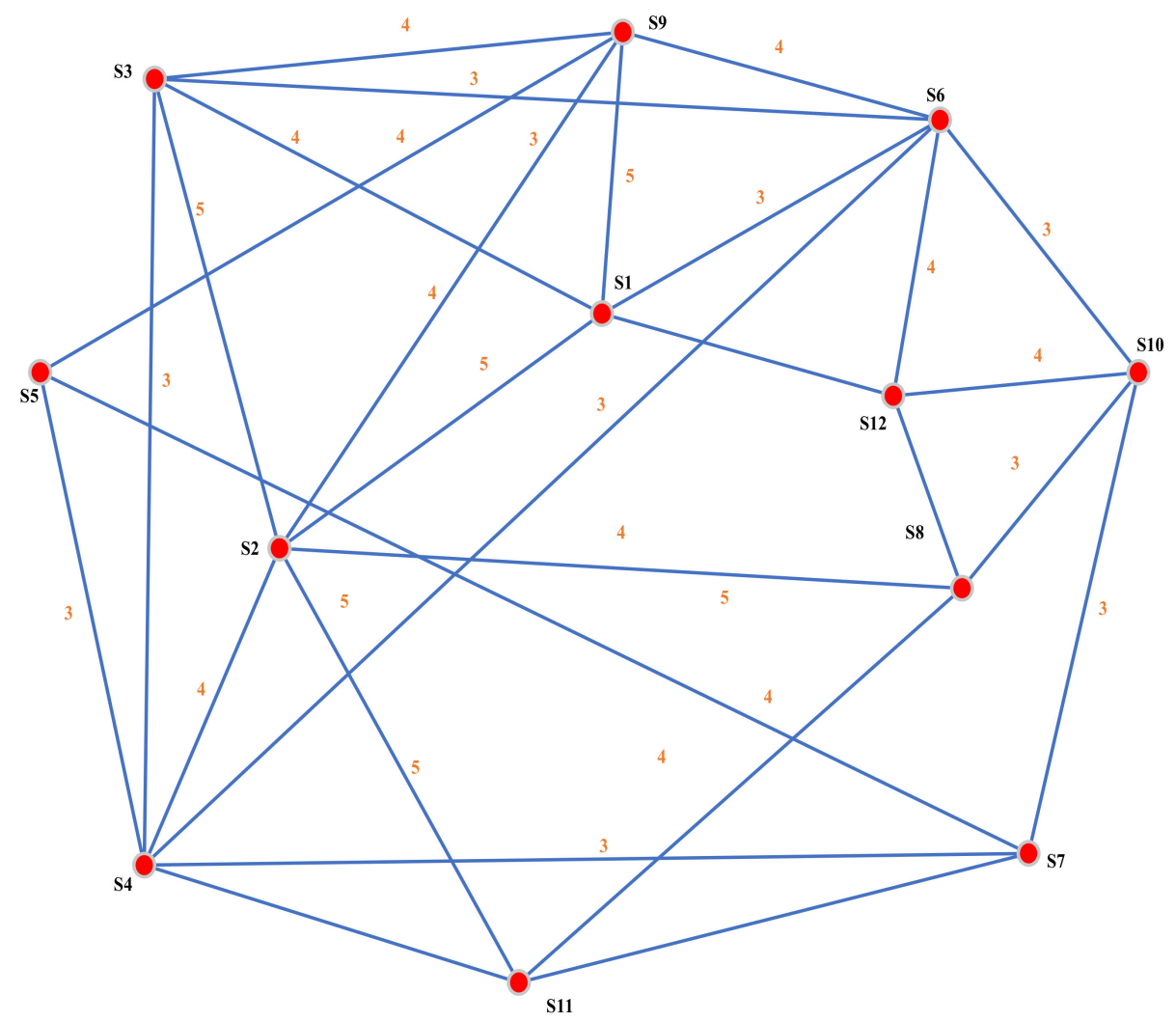

Figure 2. Social network graphs with the strength of critical employee relationships.

Table 4. Employee behaviors for each critical employee.

\begin{tabular}{|c|c|c|c|c|c|c|c|c|c|c|c|c|c|}
\hline \multirow{2}{*}{\multicolumn{2}{|c|}{ Employee Behaviors (Ci) }} & \multicolumn{12}{|c|}{ Critical Employees } \\
\hline & & S1 & S2 & S3 & S4 & S5 & S6 & S7 & S8 & S9 & S10 & S11 & S12 \\
\hline $\mathrm{C} 1$ & PMT cohesion & 5 & 6 & 4 & 5 & 5 & 6 & 4 & 2 & 6 & 3 & 8 & 5 \\
\hline $\mathrm{C} 2$ & $\begin{array}{l}\text { Identity of the } \\
\text { project culture }\end{array}$ & 0.5 & 5.9 & 0.2 & 4.9 & 0.2 & 4.9 & 0.2 & 0.5 & 1 & 2.5 & 2.8 & 1.8 \\
\hline $\mathrm{C} 3$ & $\begin{array}{l}\text { Formal behavior } \\
\text { between employees }\end{array}$ & 80 & 53 & 83 & 80 & 33 & 64 & 33 & 73 & 60 & 0 & 64 & 50 \\
\hline $\mathrm{C} 4$ & Collaborate efficacy & 0.3 & 0.5 & 0.3 & 0.3 & 0.7 & 0.4 & 0.7 & 0.3 & 0.5 & 0.4 & 1 & 0.6 \\
\hline C5 & Informal social constraints & 0.6 & 0.4 & 0.7 & 0.5 & 0.6 & 0.4 & 0.7 & 0.5 & 0.5 & 0.4 & 0.3 & 0.5 \\
\hline C6 & Reciprocity and mutual trust & 2 & 2 & 3 & 2 & 1 & 6 & 1 & 3 & 1 & 6 & 0 & 2 \\
\hline
\end{tabular}

\section{Discussion}

The case study of the selected HOPSCA project holistically implemented the methodology proposed in Section 3. 12 CEs of the HOPSCA project were identified and their interrelations and the strength of the relationships were determined by conducting the semi-structured interview. By doing these, the components of the SNA model have been obtained. Finally, the SNA graph has been generated in the UCINET platform. As a result, the employee behaviors for each critical employee are displayed in the form of a table and the value of CPR are calculated.

The results of the case study could be used to analyze the strength of the indicators for the resilience of the construction project. As we mentioned in Section 3.4, the 4R characteristics analysis of a resilient construction project could help the decision-makers understand the weakness of the construction project in building resilience and making the strategies for improvement from the following four aspects. 


\section{(1) Robustness}

When encountering disturbances and uncertainties, some connections between the CEs may be reduced. However, the alternative intermediaries could still help the CEs connect with others. This characteristic of resilience is usually referred to as robustness. The robustness of an SNA model of the construction project is characterized by the identity of the project culture ( $\mathrm{C} 2)$ and formal behavior between employees (C3). Based on the findings presented in Table 4, certain efforts could be made by the project managers or decision-makers to improve the robustness of the resilience of construction projects.

First, S1, S3, S5, S7, and S8 have lower scores of C2 than other CEs. Especially, S3, S5, and S7 own the lowest scores of 0.2 , which means that in the selected construction project, the consultant owns the weak formal internal relationship with other CEs. The weak performance in the EB C3 negatively impacts the robustness of the construction project and thus, finally forms the barriers to arriving at the CPR. Hence, it is significantly imperative to enhance the identity of the project culture for the CEs including deputy project manager, chief engineer, safety and quality engineer, construction crew, and site engineer.

Second, S5, S7, and S10 have the lowest value for the betweenness centrality of the SNA model. Especially, the betweenness centrality of S10 is 0, which means that in the selected construction project, the consultant owns the weak formal internal relationship with other CEs. The weak performance in the EB C3 negatively impacts the robustness of the construction project and thus, finally forms the barriers to arriving at the CPR. Therefore, improving the formal internal relationship and enhancing the communication and collaboration between safety and quality engineer, construction crew, and consultant to other CEs could obtain the maximum benefits for improving the robustness of the construction project.

The findings reveal an effective and intuitive way to improve the resilience of the construction project from the perspective of robustness, that is, to enhance the weak EB indicators of the CEs. Extensive efforts and care should be taken to cultivate the identity of the project culture and strengthen the formal internal relationship between the CEs. For instance, the flexible, adapted to changes and innovative organizational method for project management could help the PMT to quickly generate the project culture. Along with the process of knowledge sharing, the project culture is gradually recognized by all the PMT members. In this process, formal internal relationships which are restricted by the principles and contracts between CEs are served as the effective bridge for knowledge sharing.

\section{(2) Redundancy}

Redundancy is usually defined as the existence of replaceable elements, systems, or other analysis units which can continue to meet functional requirements in the event of interruption, degradation, or loss of function. Toward the resilience of construction projects, it means that after some subsystems of the construction project system are damaged and affected, the ability to continue to maintain the original functional status through other alternative systems. Hence, in the proposed SNA model, after the disturbances and uncertainties, the CEs could still keep connecting through alternative resources. The redundancy of an SNA model of the construction project is characterized by collaborative efficacy (C4) and informal social constraints (C5). According to the results, due strategies could be put forward to improve the redundancy of the construction project.

First, S1, S3, S4, and S8 have a lower collaborative efficacy of 0.3 than other CEs. Hence, due care should be exerted to improve the collaborative efficacy of the CEs including deputy project manager, chief engineer, cost engineer, and site engineer. Establishing the incentive mechanism, shortening the path of cooperation, and clarifying the responsibilities of CEs are significant measures to achieve better collaboration efficacy. 
Second, S2, S6, S10, and S11 have the lower value for the constraint of the SNA model. Especially, informal social constraints of S11 reach 0.3, which means it has relatively more structural holes. In the selected case study, the CEs, business manager, procurement engineer and consultant, designer, should enhance more social capital to improve necessary alternatives from the aspects of the project resources and the construction equipment.

The results indicate that improving the weak EB indicators of the CEs is critical to increasing the redundancy of the construction project which is one of the significant characteristics of the CPR. Due to the limitation of project resources, the minimum investment of the construction project should gain the maximum benefit. Hence, for the decision-makers of the selected construction project, these CEs analyzed above should be the key elements and the focus of attention.

\section{(3) Rapidity}

Rapidity is manifested in the ability to meet priorities and achieve goals, which finally is to control losses and avoid interruptions. Toward the resilience of construction projects, it means that after some subsystems of the construction project system are damaged and affected, the ability to continue to maintain the original functional status through other alternative systems. In the case study, we used density as the SNA parameter to characterize the PMT cohesion (C1). Based on the results displayed in Table 4, S8 and S10 have a relatively lower density when compared to other CEs. Therefore, to improve the rapidity of the resilient construction project, the two CEs, i.e., site engineer and consultant, should be promoted to participate in the holistic construction activities and form more communication pathways with other CEs. Their collaboration should also be emphasized. The communication barriers between the PMT members should be broken to gain more PMT cohesion.

\section{(4) Resourcefulness}

Resourcefulness is usually defined as the ability to identify problems, determine priorities, and locate resources when certain elements, systems, or other analysis units are at risk of damages. Toward the resilience of construction projects, it means that a resilient construction project with resourcefulness could quickly capture the key problems, flexibly and skillfully solve or alleviate the problems, reasonably determine priorities and locate resources when encountering the disturbances and uncertainties.

Cliques were used as the SNA parameter to characterize the EB of reciprocity and mutual trust. The results reveal that S5, S7, and S9 have low cliques which means these CEs lack enough reciprocity and mutual trust. Especially, the cliques of S11 were 0 . Therefore, intensive strategies should be implemented for the designer to promote the formation of cliques. In the present, for most construction projects in China, the designer and design institute participate in the project activities as a third party which results in a low degree of enough reciprocity and mutual trust. Moreover, the lack of reciprocity and mutual trust could negatively influence the resourcefulness of the designer and finally reduce the resilience of a construction project.

Hence, from the perspective of resourcefulness, the findings of the case study proposed a way to improve the resilience of the construction project, that is, to improve the designer's EB of reciprocity and mutual trust. Establishing shared incentives and rewards, promoting more frequent interaction between designers and other CEs, implementing knowledge sharing process, and cultivating project identity would benefit to arrive at the resourcefulness and a resilient construction project.

The findings of this study provide a perspective to measure CPR and can bring theoretical and practical benefits to the project managers. The evaluation model of CPR is a simple and useful tool to quantify the value of resilience. Thus, in future studies, dynamic research could be carried out to measure the CPR in a different phase of the life cycle. Comparative research could be conducted. On these bases, the present study made a meaningful contribution to the method to measure the resilience performance for a construction project. 
Although the construction projects are high energy-consuming and resource-consuming, the effective improvement strategies for CPR can achieve the most optimal return with minimal investments. Hence, the implements for improving the CPR from four aspects: robustness, redundancy, rapidity, and resourcefulness could bring larger benefits.

\section{Summary and Conclusions}

With the tremendous developmental potentiality for the construction industry, the way of construction project development is required to adapt to the SDGs. Due to the high energy and resource consumption for construction projects, there are a large number of uncertainties and disturbances in achieving the SDGs. Therefore, studying the construction project resilience is imperative. Meanwhile, due to the constraint of traditional lean construction project management mode, the construction project management organization are facing huge challenges and opportunities in achieving SDGs [116-118]. Therefore, it is necessary to consider more formal and informal relationships in a CPMO, where the employment relationship is typically the relationship by contractual constraints.

From these perspectives, this study applied an SNA methodology to investigate the employee behaviors for each critical employee, including deputy project manager (S1), business manager (S2), chief engineer (S3), cost engineer (S4), safety and quality engineer (S5), procurement engineer (S6), construction crew (S7), site engineer (S8), construction contractor (S9), consultant (S10), designer (S11) and supervisors (S12), in a $\mathrm{CPMO}$ and thereafter built the employee relationship network using SNA. The strength of the connections between different critical employees is demonstrated accordingly. Six parameters of SNA including density, degree centrality, betweenness centrality, efficiency, constraint, and cliques are used to model the extracted employee behaviors, namely PMT cohesion (C1), the identity of the project culture (C2), formal behavior between employees (C3), collaborate efficacy (C4), informal social constraints (C5), reciprocity and mutual trust (C6). Finally, the $4 \mathrm{R}$ characteristics analysis of the CPR is conducted. The weak EB indicators for each CE are identified and the strategies to improve the CPR are proposed, correspondingly.

The provided methods could provide a simple tool to measure the construction project resilience from the perspective of employee behavior of each critical employee in a CMPO. Based on the proposed evaluation model, the project manager could figure out the strength of EB for each CE which could be applied to different construction projects, and obtain the final CPR. The value of the CPR could be served as the indicator of status under the uncertainties and disturbance. The findings provided a simple and effective methodology to measure the CPR and also benefit the project manager to improve the CPR by exerting certain efforts to the EBs in poor performance.

Author Contributions: Conceptualization, Z.Z. and H.C.; methodology, G.W. and H.Y.; software, G.W.; validation, Z.Z. and H.C.; formal analysis, G.W. and H.C.; investigation, Z.H. and H.C.; resources, Z.Z.; data curation, Z.Z.; writing—original draft preparation, Z.H.; writing-review and editing, Z.H., G.W. and H.C.; visualization, G.W. and L.L.; supervision, H.C. and Z.Z.; project administration, Z.Z.; funding acquisition, Z.Z. All authors have read and agreed to the published version of the manuscript.

Funding: The study and APC were funded by the Natural Science Foundation of Hunan Province, grant number [2021JJ30861].

Informed Consent Statement: Informed consent was obtained from all subjects involved in the study.

Data Availability Statement: All datasets generated for this study have been included in the article.

Acknowledgments: We are very grateful for the time the reviewers voluntarily spent reviewing our manuscript. We would like to thank the constructive comments and suggestions, which have helped us to improve the manuscript. All authors consent to the acknowledgements.

Conflicts of Interest: The authors declare no conflict of interest. 


\section{References}

1. Bray, J.; McCurry, N. Unintended consequences: How the use of leed can inadvertently fail to benefit the environment. J. Green Build. 2006, 1, 152-161. [CrossRef]

2. Muench, S.T.; Anderson, J.L.; Söderlund, M. Greenroads: A sustainability performance metric for roadways. J. Green Build. 2010, 5, 114-128. [CrossRef]

3. Udawatta, N.; Zuo, J.; Chiveralls, K.; Yuan, H.; Zillante, G.; Elmualim, A. Major factors impeding the implementation of waste management in Australian construction projects. J. Green Build. 2018, 13, 101-121. [CrossRef]

4. Zuo, J.; Xia, B.; Chen, Q.; Pullen, S.; Skitmore, M. Green building rating for office buildings_Lessons learned. J. Green Build. 2016, 11, 131-146. [CrossRef]

5. Nesensohn, C.; Demir, S.T.; Bryde, D.J. Developing the true north route map as a navigational compass in a construction project management organisation. Lean Constr. J. 2013, 2013, 1-18.

6. Wu, J. Aspects of Learning in Construction Organizations: The Need for Change. In Proceedings of the Queensland University of Technology Research Week International Conference, QUT Research Week 2005, Brisbane, QLD, Australia, 4-5 July 2005.

7. Brady, D.A.; Tzortzopoulos, P.; Rooke, J.; Formoso, C.T.; Tezel, A. Improving transparency in construction management: A visual planning and control model. Eng. Constr. Archit. Manag. 2018, 25, 1277-1297. [CrossRef]

8. Li, X.K.; Wang, X.M.; Lei, L. The application of an ANP-Fuzzy comprehensive evaluation model to assess lean construction management performance. Eng. Constr. Archit. Manag. 2020, 27, 356-384. [CrossRef]

9. Xing, W.; Hao, J.L.; Qian, L.; Tam, V.W.Y.; Sikora, K.S. Implementing lean construction techniques and management methods in Chinese projects: A case study in Suzhou, China. J. Clean. Prod. 2021, 286, 124944. [CrossRef]

10. Mellado, F.; Lou, E.C.W. Building information modelling, lean and sustainability: An integration framework to promote performance improvements in the construction industry. Sustain. Cities Soc. 2020, 61, 102355. [CrossRef]

11. Muñoz-Villamizar, A.; Santos, J.; Montoya-Torres, J.; Velázquez-Martínez, J. Measuring environmental performance of urban freight transport systems: A case study. Sustain. Cities Soc. 2020, 52, 101844. [CrossRef]

12. Bae, J.; Kim, Y. Sustainable value on construction projects and lean construction. J. Green Build. 2008, 3, 155-167. [CrossRef]

13. Chiera, M.; Lupi, F.; Rossi, A.; Lanzetta, M. Lean maturity assessment in eto scenario. Appl. Sci. 2021, 11, 3833. [CrossRef]

14. Lagarda-Leyva, E.A. System dynamics and lean approach: Development of a technological solution in a regional product packaging company. Appl. Sci. 2021, 11, 7938. [CrossRef]

15. Tran, T.A.; Ruppert, T.; Abonyi, J. Indoor positioning systems can revolutionise digital lean. Appl. Sci. 2021, 11, 5291. [CrossRef]

16. Alattyih, W.; Haider, H.; Boussabaine, H. Risk factors impacting the project value created by green buildings in Saudi Arabia. Appl. Sci. 2020, 10, 7388. [CrossRef]

17. Yoo, M.; Kim, J.; Choi, C. Effects of BIM-based construction of prefabricated steel framework from the perspective of SMEs. Appl. Sci. 2019, 9, 1732. [CrossRef]

18. Chen, X.; Lu, W.; Xue, F.; Xu, J. A cost-benefit analysis of green buildings with respect to construction waste minimization using big data in Hong Kong. J. Green Build. 2018, 13, 61-76. [CrossRef]

19. Pushkar, S.; Verbitsky, O. Silver and gold leed commercial interiors: Certified projects. J. Green Build. 2019, 14, 95-113. [CrossRef]

20. He, Z.; Chen, H.; Yan, H.; Yin, Y.; Qiu, Q.; Wang, T. Scenario-Based Comprehensive Assessment for Community Resilience Adapted to Fire Following an Earthquake, Implementing the Analytic Network Process and Preference Ranking Organization Method for Enriched Evaluation II Techniques. Buildings 2021, 11, 523. [CrossRef]

21. Wang, J.; Pan, W. Influencing parameters of the life cycle cost-energy relationship of buildings. J. Green Build. 2018, 13, 103-121. [CrossRef]

22. Zezhou, W.; Yu, A.T.W.; Wang, H.; Wei, Y.; Huo, X. Driving factors for construction waste minimization: Empirical studies in Hong Kong and Shenzhen. J. Green Build. 2019, 14, 155-167.

23. Gurgun, A.P.; Arditi, D.; Vilar, P.C. Impacts of construction risks on costs in leed-certified projects. J. Green Build. 2016, $11,163-181$. [CrossRef]

24. He, Z.; Chen, H. An ism-based methodology for interrelationships of critical success factors for construction projects in ecologically fragile regions: Take korla, China as an example. Appl. Sci. 2021, 11, 4668. [CrossRef]

25. Baker, M.; Ali, M.; French, E. Leadership Diversity and Its Influence on Equality Initiatives and Performance: Insights for Construction Management. J. Constr. Eng. Manag. 2021, 147, 04021123. [CrossRef]

26. Imam, H. Roles of Shared Leadership, Autonomy, and Knowledge Sharing in Construction Project Success. J. Constr. Eng. Manag. 2021, 147, 04021067. [CrossRef]

27. Johannes, K.; Theodorus Voordijk, J.; Marias Adriaanse, A.; Aranda-Mena, G. Identifying Maturity Dimensions for Smart Maintenance Management of Constructed Assets: A Multiple Case Study. J. Constr. Eng. Manag. 2021, 147, 05021007. [CrossRef]

28. Pariafsai, F.; Behzadan, A.H. Core Competencies for Construction Project Management: Literature Review and Content Analysis. J. Civil Eng. Educ. 2021, 147, 04021010. [CrossRef]

29. Herrera, R.F.; Mourgues, C.; Alarcón, L.F.; Pellicer, E. Analyzing the Association between Lean Design Management Practices and BIM Uses in the Design of Construction Projects. J. Constr. Eng. Manag. 2021, 147, 04021010. [CrossRef]

30. Shou, W.; Wang, J.; Wu, P.; Wang, X. Lean management framework for improving maintenance operation: Development and application in the oil and gas industry. Prod. Plan. Control 2021, 32, 585-602. [CrossRef] 
31. Eldeep, A.M.; Farag, M.A.M.; Abd El-hafez, L.M. Using BIM as a lean management tool in construction processes-A case study: Using BIM as a lean management tool. Ain Shams Eng. J. 2021, 13, 101556. [CrossRef]

32. Ardila, F.; Francis, A. Spatiotemporal Planning of Construction Projects: A Literature Review and Assessment of the State of the Art. Front. Built Environ. 2020, 6, 128. [CrossRef]

33. He, Z.; Chen, H. Critical factors for practicing sustainable construction projects in environmentally fragile regions based on interpretive structural modeling and cross-impact matrix multiplication applied to classification: A case study in China. Sustain. Cities Soc. 2021, 74, 103238. [CrossRef]

34. Cheng, B.; Lu, K.; Li, J.; Chen, H.; Luo, X.; Shafique, M. Comprehensive assessment of embodied environmental impacts of buildings using normalized environmental impact factors. J. Clean. Prod. 2021, 334, 130083. [CrossRef]

35. Bamana, F.; Lehoux, N.; Cloutier, C. Simulation of a Construction Project: Assessing Impact of Just-in-Time and Lean Principles. J. Constr. Eng. Manag. 2019, 145, 05019005. [CrossRef]

36. Qin, L.; Wang, M.; Zhu, J.; Wei, Y.; Zhou, X.; He, Z. Towards Circular Economy through Waste to Biomass Energy in Madagascar. Complexity 2021, 2021, 5822568. [CrossRef]

37. Abdelmageed, S.; Zayed, T. A study of literature in modular integrated construction-Critical review and future directions. J. Clean. Prod. 2020, 277, 124044. [CrossRef]

38. Bajjou, M.S.; Chafi, A. Empirical study of schedule delay in Moroccan construction projects. Int. J. Constr. Manag. 2020, 20, 783-800. [CrossRef]

39. Erri Pradeep, A.S.; Yiu, T.W.; Zou, Y.; Amor, R. Blockchain-aided information exchange records for design liability control and improved security. Autom Constr. 2021, 126, 103667. [CrossRef]

40. Hou, C.; Wen, Y.; He, Y.; Liu, X.; Wang, M.; Zhang, Z.; Fu, H. Public stereotypes of recycled water end uses with different human contact: Evidence from event-related potential (ERP). Resour. Conserv. Recycl. 2021, 168, 105464. [CrossRef]

41. Zohar, D.; Luria, G. A multilevel model of safety climate: Cross-level relationships between organization and group-level climates. J. Appl. Psychol. 2005, 90, 616. [CrossRef]

42. Malik, S.; Taqi, M.; Martins, J.M.; Mata, M.N.; Pereira, J.M.; Abreu, A. Exploring the relationship between communication and success of construction projects: The mediating role of conflict. Sustainability 2021, 13, 4513. [CrossRef]

43. Gardounis, F.; Chong, H.Y.; Wang, X. A conceptual framework for Social Network Analysis of Building Information Modelling in construction projects. In Proceedings of the 5th International Conference on Research and Innovation in Information Systems, ICRIIS 2017, Langkawi, Malaysia, 16-17 July 2017; IEEE Computer Society: Washington, DC, USA, 2017.

44. Alaghbari, W.; Al-Sakkaf, A.A.; Sultan, B. Factors affecting construction labour productivity in Yemen. Int. J. Constr. Manag. 2019, 19, 79-91. [CrossRef]

45. Chi, B.; Lu, W.; Ye, M.; Bao, Z.; Zhang, X. Construction waste minimization in green building: A comparative analysis of LEED-NC 2009 certified projects in the US and China. J. Clean. Prod. 2020, 256, 120749. [CrossRef]

46. Cordero, A.S.; Melgar, S.G.; Márquez, J.M.A. Green building rating systems and the new framework level(s): A critical review of sustainability certification within Europe. Energies 2019, 13, 66. [CrossRef]

47. Georgiadou, M.C. An overview of benefits and challenges of building information modelling (BIM) adoption in UK residential projects. Constr. Innov. 2019, 19, 298-320. [CrossRef]

48. Zaman, U. Examining the effect of xenophobia on "transnational" mega construction project (MCP) success: Moderating role of transformational leadership and high-performance work (HPW) practices. Eng. Constr. Archit. Manag. 2020, 27, 1119-1143. [CrossRef]

49. Laurent, J.; Leicht, R.M. Practices for Designing Cross-Functional Teams for Integrated Project Delivery. J. Constr. Eng. Manag. 2019, 145, 05019001. [CrossRef]

50. Yiu, N.S.N.; Chan, D.W.M.; Shan, M.; Sze, N.N. Implementation of safety management system in managing construction projects: Benefits and obstacles. Saf. Sci. 2019, 117, 23-32. [CrossRef]

51. Zheng, J.; Wu, G.; Xie, H.; Li, H. Leadership, organizational culture, and innovative behavior in construction projects: The perspective of behavior-value congruence. Int. J. Manag. Proj. Bus. 2019, 12, 888-918. [CrossRef]

52. Cruz-González, C.; Pérez Muñoz, M.; Domingo Segovia, J. Marta's story: A female principal leading in challenge contexts. Sch. Leadersh. Manag. 2020, 40, 384-405. [CrossRef]

53. Graham, P.; Nikolova, N.; Sankaran, S. Tension between Leadership Archetypes: Systematic Review to Inform Construction Research and Practice. J. Manag. Eng. 2020, 36, 03119002. [CrossRef]

54. Ali, A.; Wang, H.; Soomro, M.A.; Islam, T. Shared Leadership and Team Creativity: Construction Industry Perspective. J. Constr. Eng. Manag. 2020, 146, 04020122. [CrossRef]

55. Fang, D.; Huang, Y.; Guo, H.; Lim, H.W. LCB approach for construction safety. Saf. Sci. 2020, 128, 104761. [CrossRef]

56. Tengan, C.; Aigbavboa, C. Validating factors influencing monitoring and evaluation in the Ghanaian construction industry: A Delphi study approach. Int. J. Constr. Manag. 2021, 21, 223-234. [CrossRef]

57. Adu, E.T.; Opawole, A. Assessment of performance of teamwork in construction projects delivery in South-Southern Nigeria. $J$. Eng. Des. Technol. 2020, 18, 230-250. [CrossRef]

58. Goodwill, J.R.; Anyiwo, N.; Williams, E.G.; Johnson, N.C.; Mattis, J.S.; Watkins, D.C. Media representations of popular culture figures and the construction of black masculinities. Psychol. Men Masc. 2019, 20, 288-298. [CrossRef] 
59. Lijauco, F.; Gajendran, T.P.D.; Brewer, G.; Rasoolimanesh, S.M. Impacts of Culture on Innovation Propensity in Small to Medium Enterprises in Construction. J. Constr. Eng. Manag. 2020, 146, 04019116. [CrossRef]

60. Lusiani, M.; Langley, A. The social construction of strategic coherence: Practices of enabling leadership. Long Range Plan. 2019, 52, 101840. [CrossRef]

61. Hartono, B.; Sulistyo, S.; Umam, M. Leadership profiles of successful project managers in Indonesia. J. Ind. Eng. Manag. 2019, 12, 274-301. [CrossRef]

62. Yap, J.B.H.; Lee, K.Y.; Skitmore, M. Analysing the causes of corruption in the Malaysian construction industry. J. Eng. Des. Technol. 2020, 18, 1823-1847. [CrossRef]

63. Meng, X. The effect of relationship management on project performance in construction. Int. J. Proj. Manag. 2012, 30, 188-198. [CrossRef]

64. Erpay, M.Y.; Sertyesilisik, B. Preliminary checklist proposal for enhancing bim-based construction project contracts. J. Inf. Technol. Constr. 2021, 26, 341-365. [CrossRef]

65. Szostek, D. Employee behaviors toward using and saving energy at work. the impact of personality traits. Energies 2021, 14, 3404 [CrossRef]

66. Xiang, L.; Tan, Y.; Jin, X.; Shen, G. Understanding stakeholders' concerns of age-friendly communities at the briefing stage: A preliminary study in urban China. Eng. Constr. Archit. Manag. 2021, 28, 31-54. [CrossRef]

67. Xue, J.; Shen, G.Q.; Yang, R.J.; Zafar, I.; Ekanayake, E.M.A.C. Dynamic Network Analysis of Stakeholder Conflicts in Megaprojects: Sixteen-Year Case of Hong Kong-Zhuhai-Macao Bridge. J. Constr. Eng. Manag. 2020, 146, 04020103. [CrossRef]

68. Bianchi, P.; Cappelletti, G.M.; Mafrolla, E.; Sica, E.; Sisto, R. Accessible tourism in natural park areas: A social network analysis to discard barriers and provide information for people with disabilities. Sustainability 2020, 12, 9915. [CrossRef]

69. Cehan, A.; Eva, M.; Iaţu, C.; Costa, C. Inquiring structure and forms of collaboration in tourism through social network analysis. Sustainability 2020, 12, 8161. [CrossRef]

70. Choi, Y.; Cho, Y.I. Learning analytics using social network analysis and Bayesian network analysis in sustainable computer-based formative assessment system. Sustainability 2020, 12, 7950. [CrossRef]

71. Franks, D.W.; Weiss, M.N.; Silk, M.J.; Perryman, R.J.Y.; Croft, D.P. Calculating effect sizes in animal social network analysis. Methods Ecol. Evol. 2021, 12, 33-41. [CrossRef]

72. Gallardo, E.C.; de Arroyabe, J.C.F.; Arranz, N. Preventing internal COVID-19 outbreaks within businesses and institutions: A methodology based on social networks analysis for supporting occupational health and safety services decision making. Sustainability 2020, 12, 4655. [CrossRef]

73. Guevara, J.; Salazar, J.; Garvin, M.J. Social Network Analysis of Road PPP Equity Markets in Canada, Chile, and the United States. J. Manag. Eng. 2020, 36, 04020058. [CrossRef]

74. Herrera, R.F.; Mourgues, C.; Alarcón, L.F.; Pellicer, E. Understanding Interactions between Design Team Members of Construction Projects Using Social Network Analysis. J. Constr. Eng. Manag. 2020, 146, 04020053. [CrossRef]

75. Nunes, M.; Abreu, A. Applying social network analysis to identify project critical success factors. Sustainability 2020, $12,1503$. [CrossRef]

76. Ludovico, N.; Dessi, F.; Bonaiuto, M. Stakeholders mapping for sustainable biofuels: An innovative procedure based on computational text analysis and social network analysis. Sustainability 2020, 12, 10317. [CrossRef]

77. Narayan, A.S.; Fischer, M.; Lüthi, C. Social Network Analysis for Water, Sanitation, and Hygiene (WASH): Application in Governance of Decentralized Wastewater Treatment in India Using a Novel Validation Methodology. Front. Environ. Sci. 2020, 7, 198. [CrossRef]

78. Prabhakar, N.; Anbarasi, L.J. Exploration of the global air transport network using social network analysis. Soc. Netw. Anal. Min. 2021, 11, 26. [CrossRef]

79. Nunes, M.; Abreu, A. Managing open innovation project risks based on a social network analysis perspective. Sustainability 2020, 12, 3132. [CrossRef]

80. Nurek, M.; Michalski, R. Combining machine learning and social network analysis to reveal the organizational structures. Appl. Sci. 2020, 10, 1699. [CrossRef]

81. Zhang, P.; Zhao, Y.; Zhu, X.; Cai, Z.; Xu, J.; Shi, S. Spatial structure of urban agglomeration under the impact of high-speed railway construction: Based on the social network analysis. Sustain. Cities Soc. 2020, 62, 102404. [CrossRef]

82. Shabani Ardakani, S.; Nik-Bakht, M. Functional Evaluation of Change Order and Invoice Management Processes under Different Procurement Strategies: Social Network Analysis Approach. J. Constr. Eng. Manag. 2021, 147, 04020155. [CrossRef]

83. Yip, W.S.; To, S. A critical analysis of sustainable micro-manufacturing from the perspective of the triple bottom line: A social network analysis. Environ. Impact Assess. Rev. 2021, 90, 106628. [CrossRef]

84. Yip, W.S.; To, S. Identification of stakeholder related barriers in sustainable manufacturing using Social Network Analysis. Sustain. Prod. Consum. 2021, 27, 1903-1917. [CrossRef]

85. Ahn, Y.H.; Pearce, A.R. Green construction: Contractor experiences, expectations, and perceptions. J. Green Build. 2007, 2, 106-122. [CrossRef]

86. Gou, Z.; Lau, S.S.Y.; Prasad, D. Market readiness and policy implications for green buildings: Case study from Hong Kong. J. Green Build. 2013, 8, 162-173. [CrossRef] 
87. Horman, M.J.; Riley, D.; Lapinski, A.R.; Korkmaz, S.; Pulaski, M.H.; Magent, C.S.; Luo, Y.; Harding, N.; Dahl, P.K. Delivering green buildings: Process improvements for sustainable construction. J. Green Build. 2006, 1, 123-140. [CrossRef]

88. Cajot, S.; Peter, M.; Bahu, J.M.; Guignet, F.; Koch, A.; Maréchal, F. Obstacles in energy planning at the urban scale. Sustain. Cities Soc. 2017, 30, 223-236. [CrossRef]

89. Kodysh, J.B.; Omitaomu, O.A.; Bhaduri, B.L.; Neish, B.S. Methodology for estimating solar potential on multiple building rooftops for photovoltaic systems. Sustain. Cities Soc. 2013, 8, 31-41. [CrossRef]

90. Al-Saeed, Y.; Edwards, D.J.; Scaysbrook, S. Automating construction manufacturing procedures using BIM digital objects (BDOs): Case study of knowledge transfer partnership project in UK. Constr. Innov. 2020, 20, 345-377. [CrossRef]

91. Molenaar, K.R.; Sobin, N.; Antillón, E.I. A synthesis of best-value procurement practices for sustainable design-build projects in the public sector. J. Green Build. 2010, 5, 148-157. [CrossRef]

92. Pearce, A.R.; Dubose, J.R.; Bosch, S.J. Green building policy options for the public sector. J. Green Build. 2007, 2, 156-174. [CrossRef]

93. Alam, M.; Zou, P.X.W.; Stewart, R.A.; Bertone, E.; Sahin, O.; Buntine, C.; Marshall, C. Government championed strategies to overcome the barriers to public building energy efficiency retrofit projects. Sustain. Cities Soc. 2019, 44, 56-69. [CrossRef]

94. Wuni, I.Y.; Shen, G.Q. Critical success factors for modular integrated construction projects: A review. Build. Res. Inf. 2020, 48, 763-784. [CrossRef]

95. MacDougall, C. Natural building materials in mainstream construction: Lessons from the U.K. J. Green Build. 2008, 3, 3-14. [CrossRef]

96. Ross, B.; López-Alcalá, M.; Small Iii, A.A. Modeling the private financial returns from green building investments. J. Green Build 2007, 2, 97-105. [CrossRef]

97. Doulos, L.T.; Sioutis, I.; Kontaxis, P.; Zissis, G.; Faidas, K. A decision support system for assessment of street lighting tenders based on energy performance indicators and environmental criteria: Overview, methodology and case study. Sustain. Cities Soc. 2019, 51, 101759. [CrossRef]

98. Huo, X.; Yu, A.T.W. Analytical review of green building development studies. J. Green Build. 2017, 12, 130-148. [CrossRef]

99. Schroepfer, T.; Hee, L. Emerging forms of sustainable urbanism: Case studies of vauban freiburg and solarcity linz. J. Green Build. 2008, 3, 67-76. [CrossRef]

100. Hama, S.M.L.; Kumar, P.; Harrison, R.M.; Bloss, W.J.; Khare, M.; Mishra, S.; Namdeo, A.; Sokhi, R.; Goodman, P.; Sharma, C. Four-year assessment of ambient particulate matter and trace gases in the Delhi-NCR region of India. Sustain. Cities Soc. 2020, 54, 102003. [CrossRef]

101. Durdyev, S.; Hosseini, M.R. Causes of delays on construction projects: A comprehensive list. Int. J. Manag. Proj. Bus. 2020, 13, 20-46. [CrossRef]

102. Luong, D.L.; Tran, D.H.; Nguyen, P.T. Optimizing multi-mode time-cost-quality trade-off of construction project using opposition multiple objective difference evolution. Int. J. Constr. Manag. 2021, 21, 271-283. [CrossRef]

103. Cook, E.A. Green site design: Strategies for storm water management. J. Green Build. 2007, 2, 46-56. [CrossRef]

104. Grant, E.J.; Jones, J.R. A decision-making framework for vegetated roofing system selection. J. Green Build. 2008, 3, 137-152. [CrossRef]

105. Seo, S.; Tucker, S.; Newton, P. Automated material selection and environmental assessment in the context of 3D building modelling. J. Green Build. 2007, 2, 51-61. [CrossRef]

106. Ottosen, T.B.; Kumar, P. The influence of the vegetation cycle on the mitigation of air pollution by a deciduous roadside hedge. Sustain. Cities Soc. 2020, 53, 101919. [CrossRef]

107. Austin, G. Case study and sustainability assessment of Bo01, Malmö, Sweden. J. Green Build. 2013, 8, 34-50. [CrossRef]

108. Lehmann, S. Towards a sustainable city centre: Integrating ecologically sustainable development (esd) principles into Urban renewal. J. Green Build. 2006, 1, 86-104. [CrossRef]

109. Li, X.; Strezov, V.; Amati, M. A qualitative study of motivation and influences for academic green building developments in Australian universities. J. Green Build. 2013, 8, 166-183. [CrossRef]

110. Yadav, G.; Mangla, S.K.; Luthra, S.; Rai, D.P. Developing a sustainable smart city framework for developing economies: An Indian context. Sustain. Cities Soc. 2019, 47, 101462. [CrossRef]

111. Alvarez, L.; Borsi, K.; Rodrigues, L. The role of social network analysis on participation and placemaking. Sustain. Cities Soc. 2017, 28, 118-126. [CrossRef]

112. Hosseini, M.; El-Diraby, T.; Shalaby, A. Supporting sustainable system adoption: Socio-semantic analysis of transit rider debates on social media. Sustain. Cities Soc. 2018, 38, 123-136. [CrossRef]

113. Lei, Y.; Zhou, Y.; Shi, J. Overlapping communities detection of social network based on hybrid C-means clustering algorithm. Sustain. Cities Soc. 2019, 47, 101436. [CrossRef]

114. Tian, Y.; Wang, L. Mutualism of intra- and inter-prefecture level cities and its effects on regional socio-economic development: A case study of Hubei Province, Central China. Sustain. Cities Soc. 2019, 44, 16-26. [CrossRef]

115. Bruneau, M.; Chang, S.E.; Eguchi, R.T.; Lee, G.C.; O’Rourke, T.D.; Reinhorn, A.M.; Shinozuka, M.; Tierney, K.; Wallace, W.A.; Von Winterfeldt, D. A framework to quantitatively assess and enhance the seismic resilience of communities. Earthq. Spectra 2003, 19, 733-752. [CrossRef] 
116. Li, Y.Y.; Chen, P.H.; Seng Chew, D.A.; Teo, C.C.; Ding, R.G. Exploration of critical external partners of Architecture/Engineering/Construction (AEC) firms for delivering green building projects in Singapore. J. Green Build. 2012, 7, 193-209. [CrossRef]

117. Russell, J.A.; Helms, C.R.; Everhart, R.C.; Miller, D.J. Applying project based learning in an undergraduate design and construction program at appalachian state university. J. Green Build. 2018, 13, 147-165. [CrossRef]

118. Tam, V.W.Y.; Le, K.N. Predicting environmental performance of construction projects by using least-squares fitting method and robust method. J. Green Build. 2007, 2, 143-155. [CrossRef] 